\title{
HEALTH POLICY \\ Development and Impact of a Novel Academic Primary Care Compensation Model
}

\author{
Elizabeth Trowbridge, MD ${ }^{7,5}$, Christie M. Bartels, MD MS², Steven Koslov, MD ${ }^{3,5}$, \\ Sandra Kamnetz, MD 4.5 , and Nancy Pandhi, MD MPH PhD 4.5
}

'Division of General Internal Medicine, Department of Medicine, University of Wisconsin School of Medicine and Public Health, Madison, WI, USA; ${ }^{2}$ Division of Rheumatology, Department of Medicine, University of Wisconsin School of Medicine and Public Health, Madison, WI, USA; ${ }^{3}$ Division of General Pediatrics and Adolescent Medicine, Department of Pediatrics, University of Wisconsin School of Medicine and Public Health, Madison, WI USA; ${ }^{4}$ Department of Family Medicine, University of Wisconsin School of Medicine and Public Health, Madison, WI, USA; ${ }^{5}$ Primary Care Academics Transforming Healthcare Collaborative, UW Health, Madison, WI, USA.

BACKGROUND: Traditional productivity-based compensation models do not align well with newer populationbased approaches to primary care. There are few published examples of academic general internal medicine compensation models that explicitly reward population health management, including care for patients between visits.

OBJECTIVE: To describe the development and implementation of an academic general internal medicine compensation plan based upon actual work performed, compare satisfaction across primary care specialties, and evaluate work-related outcomes.

DESIGN: Observational study.

PARTICIPANTS: Forty-seven general internists who practice in affiliated academic and community clinics.

MAIN MEASURES: Clinician satisfaction with compensation plan, workforce stability, panel data, and productivity.

KEY RESULTS: The compensation plan change was associated with higher provider satisfaction. Sixty-five percent $(31 / 47)$ of participants within general internal medicine reported being satisfied or very satisfied, as compared to $24 \%$ (22/90 participants) for family medicine and $22 \%$ (5/23 participants) for general pediatrics $(p<0.05)$. In the first 4 years of the compensation plan change, no general internists left to join other local groups. General internal medicine increased its number of physicians by $19 \%$. The number of established general internists accepting new patients increased from 17 to $48 \%$, while the relative value units per full-time equivalent declined by $3 \%$.

CONCLUSIONS: An equitable compensation model that aligns with population management goals and work performed outside the clinical visit can lead to improved satisfaction and retention of faculty in an academic general internal medicine division, along with improved access for the patient population.

KEY WORDS: Primary care; Physician satisfaction; Workforce.

J Gen Intern Med 30(12): 1865-70

DOI: $10.1007 /$ s11606-015-3410-7

(C) Society of General Internal Medicine 2015

Received October 14, 2014

Revised February 23, 2015

Accepted April 27, 2015

Published online June 13, 2015

\section{INTRODUCTION}

The goals of primary care are evolving toward a system that prioritizes population-based care for groups of patients outside the traditional clinical visit. ${ }^{1-3}$ However, productivity-based compensation models for academic primary care physicians do not align with the scope of work required for populationbased care. The literature has documented the unseen work performed by primary care clinicians who are caring for a panel of patients, including the hours spent on non-visit-based care that typically are not included in compensation measures (e.g., relative value units [RVUs]). ${ }^{4-6}$ This demand on clinician time without adequate compensation has led to physician dissatisfaction $^{7,8}$ and poor primary care recruitment and retention at a national level, ${ }^{9}$ particularly among general internal medicine faculty clinicians at academic medical centers. ${ }^{10}$ The resulting primary care physician shortage will adversely affect patient care, learners, and academic medical centers. In order to recruit and retain academic primary care physicians, it is critical to align and enhance compensation with the goals of population management and the actual work that is being performed.

Several methods have been described for creating clinical compensation models that better align with the work performed in primary care. Popular current options include salary models or blended payment options that can adapt to the highly variable primary care environments. ${ }^{11}$ Blended models reward productivity and provide incentives for achievement in areas such as quality metrics or patient satisfaction. ${ }^{12-16}$ However, there are few published examples of models that explicitly reward care for patients between visits, and a dearth of information around models targeting academic physicians.

National trends in primary care physician workforce shortages and an emphasis on population health necessitate change. The diversion of general internists to hospitalists, in part fueled by hospitalist higher median salaries, has further depleted the supply of primary care physicians. This divide has been compounded by higher median hospitalist salary growth. However, even prior to the hospitalist movement, ambulatory primary care physicians have had concerns with productivity- 
based RVUs, ${ }^{17,18}$ which may not correlate with full-time equivalent (FTE) or actual effort. ${ }^{19}$ There has also been a rising interest in reforming primary care compensation to incentivize quality and improve delivery of population health. ${ }^{20-22}$

In this paper, we describe the development and evaluation of a novel compensation model for a general internal medicine division at a large Midwestern academic medical center. This compensation plan aimed to reward the total work required for population management, as well as improve physician recruitment and retention. The model moves away from face-to-face visit compensation to a panel-based compensation paradigm that also rewards non-face-to-face care (e.g., telephone calls) and population management (e.g., team-based outreach). We define the model development process and present beforeand-after outcomes, including physician retention and impact on productivity and patient access. We compare physician satisfaction within general internal medicine to other primary care specialties at the institution.

\section{PROCESS AND METHODS}

\section{Setting}

UW Health is a public academic health system consisting of a school of medicine and public health, a non-profit hospital, and a large multispecialty physician group. This delivery system is one of the largest academic medical centers in the country, providing primary care for approximately 279,000 patients. Primary care physicians constitute $22 \%$ of the 1280 members of the largest medical group in the state. UW Health primary care physicians comprise family physicians, pediatricians and general internists. At the time of this study, there were 56 general internal medicine (GIM) faculty members caring for 77,000 adult patients annually in both academic and community clinic settings. Of these 56 faculty members, 47 had been employed by the organization for at least 2 years during the study period (2009-2013), and were thus eligible for inclusion in the study.

In 2009, local GIM physician leadership faced four key stressors: [1] the existing clinical compensation plan was not aligned with clinical work or the goals of population health management; [2] there was growing dissatisfaction with the $100 \%$ RVU-based compensation model; [3] GIM physicians had lower salaries than starting hospitalist physicians and their fellow primary care physicians in family medicine; and [4] there was a need to stabilize and recruit into the general internal medicine workforce.

Prior to the implementation of the new compensation model in 2009, GIM physician clinical compensation was based wholly on RVU productivity. Full-time hospitalist starting salaries were $\$ 25,000$ higher and family medicine physician salaries were $\$ 20,000$ higher. $^{23}$ Recruitment competition compounded compensation-related stressors, leading to significant attrition of general internists to locally competing health systems and hospitalist groups. This attrition led to approximately 14,000 patients without a primary care physician.

The culmination of these factors superimposed on national primary care physician shortages created an opportunity to reenvision a mixed-model clinical compensation system. As a stopgap measure, GIM salaries were stabilized through a 1year support stipend while the new compensation plan was devised. Focus then shifted to designing and implementing a rational compensation model to accomplish the goals of improving GIM recruitment, retention, and offering quality population health.

\section{Engaging Consultants to Prioritize Needs and Empower Stakeholders}

A national consulting firm was hired to help evaluate the current state of compensation and to design potential alternative models. Consultants initially met with organizational and divisional GIM leadership to establish goals and project timelines. They then conducted four focus groups, each comprising 8-10 GIM faculty, in order to identify the most important aspects of a primary care compensation plan. Discussions were guided by compensation self-assessment materials ${ }^{24}$ and culminated in the creation of prioritized lists of compensation issues. Themes from these lists were then identified and combined, resulting in four priorities on which to base the new compensation model: [1] to align with the true work of caring for a panel of medically-homed patients; [2] to increase clinical salaries commensurate with peers; [3] to enable successful recruitment and retention of GIM physicians; and [4] to increase physician satisfaction with compensation. In addition to the focus group process, GIM leadership engaged GIM faculty in discussions of minimum clinical standards, including defining clinical FTE and citizenship standards (Table 1) upon which clinical salary would be based. These discussions took place in meetings over 6 months. Transparency and stakeholder engagement, from executives to GIM faculty, were key tenets of this process.

Table 1 General Internal Medicine Clinical Standards for 1 FullTime Equivalent Salary

\footnotetext{
I. Clinical requirements

- Complete 45 weeks of clinic a year (make-up sessions if necessary)

- Achieve required visit quota of $3 \mathrm{~h}$ of clinic visits per half-day session

- Reach $85 \% \pm 10 \%$ benchmark RVUs

- Achieve weighted panel size of 1800-2000

- Complete documentation of clinic visits and billing within 72-h institutional guideline

- Manage electronic health record tasks per institutional standards (release results to patient portal within 4 days and answer phone or electronic messages the same day)

- Participate in individual and clinic team-based quality improvement

II. Citizenship requirements

- Attend 6 division meetings per year

- Attend 6 to 8 GIM division Grand Rounds per year

- Present at GIM division Grand Rounds at least every other year

- Participate in 2 citizenship activities per year (e.g., committees, recruitment, task forces)
}

$R V U$ relative value unit, GIM general internal medicine 


\section{Deciding on a Model}

Using this faculty input, GIM leadership proposed three separate compensation models (Table 2). These models were presented to faculty during a division meeting, and an anonymous email vote in support of one of three potential models was conducted in July 2009 , requiring $75 \%$ support to pass. The final model recommendation was then presented to the academic institution faculty compensation committee by the GIM clinical vice chair for institutional approval.

The third, and most novel, model encouraged panel management, team care, access, outreach, and quality. It involved three components: [1] $50 \%$ clinical salary base, [2] $25 \%$ dependent on panel size, and [3] $25 \%$ dependent on productivity. In this model, salary is adjusted every 6 months based on individual provider data, and up to half of the base salary is at risk if minimum standards are not met (Table 1). Standards and penalties for panel size and RVU targets were also defined by group consensus (Tables 3 and 4). Monthly individual metrics, online compensation calculator tools, and semiannual reviews gave providers opportunities to review their data and respond if they were not meeting minimum clinical standards. Potential response options included opening panels to accept new patients (thereby increasing panel size) or increasing RVU productivity by expanding the number of appointments available for scheduling.

\section{Evaluation}

Observations began in 2009, and outcomes were measured through July 2013. Physician surveys and retention data were used to analyze clinician satisfaction with compensation and workforce stability.

\section{Clinician Satisfaction}

One year following compensation plan implementation, a follow-up online survey was conducted to measure clinician satisfaction with the compensation plan. All primary care physicians (general internal medicine, family medicine, and general pediatric and adolescent medicine) at the institution were surveyed to assess satisfaction with compensation. The response rate was $60 \%$ for all primary care physicians (146 responses), including $55 \%$ for GIM (31 responses), $52 \%$ for general pediatric and adolescent medicine (23 responses), and

Table 2 Proposed Compensation Models

\begin{tabular}{ll}
\hline \hline Model & Model components \\
\hline Model 1 & $100 \%$ of RVU benchmark \\
Model 2 & $80 \%$ RVU \\
& $20 \%$ weighted panel size \\
Model 3 & $50 \%$ salary with clinical requirements \\
& $25 \%$ RVU RVU benchmark) \\
& $25 \%$ weighted panel size \\
\hline
\end{tabular}

$R V U$ relative value unit

*Panels weighted by patient age, gender, and payer type
Table 3 Panel Size Sliding Scale Adjustment Table

\begin{tabular}{lll}
\hline Percent of panel target & Panel size & Salary decrease \\
\hline $90 \%$ and above & Over 1620 & $0 \%$ \\
85 to $89 \%$ & 1530 to 1619 & $6 \%$ \\
80 to $84 \%$ & 1440 to 1529 & $9 \%$ \\
75 to $79 \%$ & 1350 to 1439 & $12 \%$ \\
70 to $74 \%$ & 1260 to 1349 & $15 \%$ \\
65 to $69 \%$ & 1170 to 1259 & $18 \%$ \\
60 to $64 \%$ & 1080 to 1169 & $21 \%$ \\
55 to $59 \%$ & 990 to 1079 & $24 \%$ \\
Less than $54 \%$ & 0 to 989 & $24 \%$
\end{tabular}

$78 \%$ (90 responses) for family medicine. Respondents were asked two questions about compensation as part of this email survey: "In general, how satisfied are you with your compensation plan structure?" and "In general, how satisfied are you with your annual salary?" Responses were scored on a Likert scale of 1 to 5 (very dissatisfied, dissatisfied, neutral, satisfied, and very satisfied). Survey data were analyzed using the Mann-Whitney test to compare the responses of general internal medicine physicians to those of family medicine and general pediatric and adolescent medicine physicians. The Mann-Whitney test was used due to the non-parametric nature of the data and the small and disproportionate sample sizes. ${ }^{25}$ Responses were considered statistically significant at $p<0.05$.

\section{Workforce Metrics}

Workforce stability was measured by calculating the attrition rate. We used only established physicians for this calculation. We defined established physicians as those employed between 2009 and 2013, and who had been employed by the organization for at least 2 years (no longer on salary guarantee). Physician growth was calculated by summing the number of established physicians (as defined above) to the number of physicians on salary guarantee.

\section{Panel Management and Productivity Metrics}

An "open panel" is defined as the ability to accept new patients. Providers were able to electively close panels at 1800 patients, or could reopen panels to accommodate access for additional patients.

Table 4 RVU Sliding Scale Adjustment Table

\begin{tabular}{lll}
\hline Percent of RVU benchmark & RVU total & Salary decrease \\
\hline $76 \%$ and above & Over 3413 & $0 \%$ \\
71 to $75 \%$ & 3231 to 3413 & $6 \%$ \\
66 to $70 \%$ & 3003 to 3230 & $9 \%$ \\
61 to $65 \%$ & 2776 to 3002 & $12 \%$ \\
56 to $60 \%$ & 2548 to 2775 & $15 \%$ \\
51 to $55 \%$ & 2321 to 2547 & $18 \%$ \\
46 to $50 \%$ & 2093 to 2320 & $21 \%$ \\
41 to $45 \%$ & 1866 to 2092 & $24 \%$ \\
0 to $40 \%$ & 0 to 1865 & $24 \%$ \\
\hline
\end{tabular}

$R V U$ relative value unit 
RVUs reported here were calculated by the organization using the Medicare resource-based relative value scale (RBRVS). When RBRVS data is not available for a specific code, the organization uses a historical average charge. RVUs were reviewed and reported to providers semiannually, both overall and relative to FTE. One clinical FTE is defined as 9 half-days providing direct patient care in a clinic setting and 1 half-day of administrative time.

RVUs per FTE were determined by using the total RVUs documented by GIM physicians divided by the clinical FTEs of these physicians. A paired t test was used to compare RVUs per FTE for the period prior to the implementation of the compensation plan (January-June 2010) to the period following the implementation of the compensation plan (July-December 2012). Statistical significance was determined at $p<0.05$.

\section{Role of Funding Source}

The study was supported by institutional funding from the National Center for Advancing Translational Sciences (NCAT S). In addition, two authors were supported by National Institutes of Health $(\mathrm{NIH})$ career development awards. The funding sources had no role in the study design or analysis and interpretation of the data.

\section{RESULTS}

\section{Compensation Plan Outcomes}

Forty-five of 47 eligible GIM faculty (96\%) participated in the anonymous yes/no email vote in support of the new model. Voting resulted in a $96 \%$ approval rating for the third model, which had a fixed base salary and blended RVU and weighted panel adjustment. Notably, this support was well above the $75 \%$ approval needed.

In the initial 4 years of plan implementation, no physicians have left to join local groups or to become hospitalists, compared to $10 \%$ of GIM physicians $(n=9)$ leaving between 2007 and 2009. GIM retained and increased its number of physicians by $19 \%$ from 2009 to 2013 .

As shown in Table 5, following implementation of the new model, GIM physicians expressed greater satisfaction with their compensation plan (65\% were very satisfied/satisfied) as compared to physicians in pediatrics (22\%) and family medicine $(24 \%)$. They were also more satisfied with their annual salaries than physicians in other primary care specialties (64\% versus $34 \%$ in pediatrics and $28 \%$ in family medicine reporting being very satisfied/satisfied). These differences were statistically significant $(p<0.05)$. Satisfaction with compensation was not measured at the individual level, so change in satisfaction of individual physicians was not measurable.

From 2009 to 2013, open panels increased from 17 to $48 \%$, thereby improving patient access to care. After implementation of the plan in 2010, RVUs per FTE declined by $3 \%$ over the next 18 months. This decline was statistically significant $(p<0.0001)$.

\section{DISCUSSION}

This new compensation model for academic faculty in internal medicine has several noteworthy features. First, explicitly using panel size as a measure of productivity links face-toface physician work to the work that occurs outside the visit. Second, the model offers both a secure salary and incentive to increase access via expanded panel sizes and/or increased numbers of visits. Finally, the model aligns well with national movements such as the patient-centered medical home and accountable care organizations, ${ }^{26}$ where goals are to improve population health and ensure quality.

Critical components of the model development process included multilevel stakeholder engagement, transparency, external consultant expertise, and consensus regarding plan selection and implementation of minimum clinical standard metrics. Positive outcomes after model implementation included improved physician retention, satisfaction with compensation, and a larger percentage of open panels to accommodate more access for patients. Some degree of RVU decline had been anticipated due to the shift from face-to-face visitbased care to population management occurring outside of visits. ${ }^{6}$ However, the magnitude of declines over time and other unintended consequences merit further evaluation. The local impetus for change mirrored national trends of low primary care physician compensation and declining job satisfaction. ${ }^{7-10}$ A recent review concluded that the ideal compensation scheme for primary care physicians would "offer the security of a base salary as well as an additional bonus

Table 52011 Compensation Survey Results of Institution-Wide Primary Care Physicians

\begin{tabular}{|c|c|c|c|c|c|c|c|}
\hline & Very dissatisfied & Dissatisfied & Neutral & Satisfied & Very satisfied & $\mathbf{N} / \mathbf{A}$ & $\overline{p \text { value }}$ \\
\hline \multicolumn{8}{|c|}{ Satisfaction with compensation plan structure } \\
\hline Internal medicine $(n=31)$ & $6 \%$ & $6 \%$ & $23 \%$ & $42 \%$ & $23 \%$ & $0 \%$ & \\
\hline Family medicine $(n=90)$ & $14 \%$ & $43 \%$ & $19 \%$ & $20 \%$ & $4 \%$ & $0 \%$ & $<\mathbf{0 . 0 0 0 1}$ \\
\hline Pediatrics $(n=23)$ & $9 \%$ & $39 \%$ & $26 \%$ & $22 \%$ & $0 \%$ & $4 \%$ & $<\mathbf{0 . 0 1}$ \\
\hline \multicolumn{8}{|l|}{ Satisfaction with annual salary } \\
\hline Internal medicine $(n=31)$ & $3 \%$ & $6 \%$ & $27 \%$ & $32 \%$ & $32 \%$ & $0 \%$ & \\
\hline Family medicine $(n=90)$ & $8 \%$ & $43 \%$ & $21 \%$ & $24 \%$ & $4 \%$ & $0 \%$ & $<0.0001$ \\
\hline Pediatrics $(n=23)$ & $4 \%$ & $26 \%$ & $36 \%$ & $30 \%$ & $4 \%$ & $0 \%$ & $<0.01$ \\
\hline
\end{tabular}

Bold represents mode response 
rewarded for high performance,"27 as reflected in our model. Other large physician groups such as Group Health ${ }^{14}$ use blended salary and productivity incentives in their models, although there has been limited reporting of work-related outcomes.

A number of lessons learned from this work can be applied to transformative change in academic medical centers. ${ }^{28}$ One was the need to capitalize on urgent opportunities for change. At UW Health, that urgency was the dire situation of primary care physician recruitment and retention coupled with the lack of primary care access for 14,000 patients. These issues created an environment where change was critical. Second, outside experts allowed for a credible data-driven dialogue with organizational leaders and individual providers. The third important lesson was the need to engage stakeholders through mutually defining clinical standards and concrete deliverable outcomes. This democratic process engendered trust among clinicians, allowing them to transition from a productivitybased model to one that was more salary-based. Lastly, alignment with strategic priorities such as improved access and population health delivery motivated organizational leadership to support change.

In addition to these lessons, a few unintended consequences were illustrative as well. While providers opened their panels to accept new patients, and access improved when panel size was incentivized, visit-based RVUs decreased with the move away from productivity-based compensation. Of note, the penalty for not achieving RVU targets was not enforced until productivity fell less to than $76 \%$. The trajectory of RVU declines might have changed if this target had been increased. Secondly, staffing ratios for clinic support staff had historically been determined by visit volume. The same amount of staffing support from registered nurses and medical assistants was required in order to provide population management under this new model. Organizational and clinic leaders needed to be educated about these new staffing roles. Moreover, declining RVUs needed to be viewed in light of impending national reimbursement changes emphasizing value over volume.

The outcomes evaluated are subject to certain limitations. This study was centered on GIM and its compensation plan. Investigators did not have access to comparable RVU or panel access data for either pediatrics or family medicine for the study's time period. Thus, while we can assess relative differences in reported satisfaction, and we can report improved access for GIM physicians, with a small decrease in RVU per FTE, we cannot compare these changes to pediatrics or family medicine practices. However, given that there were no major changes in the pediatrics or family medicine departments during this period, it is reasonable to attribute changes in GIM access and RVUs per FTE to the major changes in the GIM compensation plan. With regard to physician satisfaction, satisfaction with compensation was relative to other primary care divisions that were purely productivity-based rather than with pre/post GIM data. Secondly, the organization did not formally survey GIM physicians prior to the compensation plan change. Next, satisfaction with compensation was not measured at the individual level, so pre/post change in satisfaction of individual physicians was not measurable. Also, there were only two survey items that were relevant to physician satisfaction with compensation. Additionally, results from this single public academic health system may not be generalizable to all settings. In particular, UW Health was financially able to redirect funds towards this compensation model, which were estimated to involve an increase of $\$ 1.4$ million across 31 clinical FTEs. The organization had a significant proportion of capitated members through an institution-owned insurance company and through participation in a Medicare shared savings plan, further incentivizing a transition away from a productivity-based model, in contrast to incentives in a fee-for-service system. Finally, these changes applied to clinical salary only and did not apply to teaching or other non-clinical academic work. Nonetheless, based on the success of this model in retaining general internists, increasing access capacity for new patients, and improving physician satisfaction with compensation, our organization developed a similar compensation model across primary care.

System-wide alignment of compensation and organizational vision and mission offers a means of achieving quality and providing a stable, satisfied primary care workforce within an academic medical center. An equitable compensation model that is aligned with population management and work performed outside the clinical visit can lead to improved retention and satisfaction among faculty in an academic general internal medicine division. In this study, the transparency of the process and consistent stakeholder input were keys to success. Physicians reported being fairly compensated, experiencing higher compensation satisfaction than peers, and being more open to accommodating new patients after the model was implemented. While the capacity to serve new patients increased, RVU performance fell. Future research on the development and outcomes of novel compensation models such as this will be critical for providing a much-needed base of evidence for academic healthcare reform. The challenges of aligning compensation with the goals of panel management within patient-centered medical homes and accountable care organizations will continue to demand innovation.

ACKNOWLEDGMENTS: This project was supported by the Health Innovation Program, the University of Wisconsin School of Medicine and Public Health from The Wisconsin Partnership Program, and the Community Academic Partnerships core of the University of Wisconsin Institute for Clinical and Translational Research (UW ICTR) through the National Center for Advancing Translational Sciences (NCATS), grant UL1TROOO427. The content is solely the responsibility of the authors and does not necessarily represent the official views of the NIH. In addition, C. Bartels is supported by a National Institute of Arthritis and Musculoskeletal and Skin Diseases Career Development Award, grant number K23AR062381; N. Pandhi is supported by a National Institute on Aging Mentored Clinical Scientist Research Career Development Award, grant number K08 AG029527. The authors thank Zaher Karp for editing.

Conflict of Interest: The authors declare that they do not have a conflict of interest. 
Corresponding Author: Elizabeth Trowbridge, MD; Division of General Internal Medicine, Department of Medicine, University of Wisconsin School of Medicine and Public Health, 2828 Marshall Court, Suite 100, Madison, WI 53705, USA (e-mail: brt@medicine.wisc.edu).

\section{REFERENCES}

1. Nutting PA, Miller WL, Crabtree BF, Jaen CR, Stewart EE, Stange KC. Initial lessons from the first national demonstration project on practice transformation to a patient-centered medical home. Ann Fam Med. 2009;7:254-60.

2. Reid RJ, Coleman K, Johnson EA, et al. The Group Health medical home at year two: cost savings, higher patient satisfaction, and less burnout for providers. Health Aff (Millwood). 2010;29:835-43.

3. Reid RJ, Fishman PA, Yu O, et al. Patient-centered medical home demonstration: a prospective, quasi-experimental, before and after evaluation. Am J Manage Care. 2009;15:e71-87.

4. Chen MA, Hollenberg JP, Michelen W, Peterson JC, Casalino LP. Patient care outside of office visits: a primary care physician time study. J Gen Intern Med. 2011;26:58-63.

5. Farber J, Siu A, Bloom P. How much time do physicians spend providing care outside of office visits? Ann Intern Med. 2007;147:693-8.

6. Gottschalk A, Flocke SA. Time spent in face-to-face patient care and work outside the examination room. Ann Fam Med. 2005;3:488-93.

7. Keating NL, Landon BE, Ayanian JZ, Borbas C, Guadagnoli E. Practice, clinical management, and financial arrangements of practicing generalists. J Gen Intern Med. 2004; 19:410-8.

8. Grembowski D, Ulrich CM, Paschane D, et al. Managed care and primary physician satisfaction. J Am Board Fam Pract. 2003; 16:383-93.

9. Lewandowski S, O'Connor PJ, Solberg LI, Lais T, Hroscikoski M, SperlHillen JM. Increasing primary care physician productivity: a case study. Am J Manage Care. 2006;12:573-6.

10. Lowenstein SR, Fernandez G, Crane LA. Medical school faculty discontent: prevalence and predictors of intent to leave academic careers. BMC Med Educ. 2007;7:37.

11. Grumbach $\mathbf{K}$. The patient-centered medical home is not a pill: implications for evaluating primary care reforms. JAMA Intern Med. 2013.

12. Lee TH, Bothe A, Steele GD. How Geisinger structures its physicians' compensation to support improvements in quality, efficiency, and volume. Health Aff (Millwood). 2012;31:2068-73.

13. Andreae MC, Freed GL. Using a productivity-based physician compensation program at an academic health center: a case study. Acad Med. 2002;77:894-9.
14. Ralston JD, Martin DP, Anderson ML, et al. Group Health Cooperative's transformation toward patient-centered access. Med Care Res Rev. 2009;66:703-24.

15. Tarquinio GT, Dittus RS, Byrne DW, Kaiser A, Neilson EG. Effects of performance-based compensation and faculty track on the clinical activity, research portfolio, and teaching mission of a large academic department of medicine. Acad Med. 2003;78:690-701.

16. Willis DR, Kelton GM, Saywell RM Jr, Kiovsky RD. An incentive compensation system that rewards individual and corporate productivity. Fam Med. 2004;36:270-8.

17. Meyer H. Report from the field. Group Health's move to the medical home: for doctors, it's often a hard journey. Health Aff (Millwood). 2010;29:84451.

18. Solomon J. How strategies for managing patient visit time affect physician job satisfaction: a qualitative analysis. J Gen Intern Med. 2008;23:775-80.

19. Fairchild DG, McLoughlin KS, Gharib S, et al. Productivity, quality, and patient satisfaction: comparison of part-time and full-time primary care physicians. J Gen Intern Med. 2001;16:663-7.

20. Goroll AH, Berenson RA, Schoenbaum SC, Gardner LB. Fundamental reform of payment for adult primary care: comprehensive payment for comprehensive care. J Gen Intern Med. 2007;22:410-5.

21. Goroll AH, Schoenbaum SC. Payment reform for primary care within the accountable care organization: a critical issue for health system reform. JAMA. 2012;308:577-8.

22. Schroeder SA, Frist w. Phasing out fee-for-service payment. N Engl J Med. 2013;368:2029-32.

23. Medical Group Management Association, American College of Medical Practice Executives. MGMA and SHM Survey: Median compensation up slightly for hospitalists. Available at: http://www.mgma.com/Press/ MGMA-and-SHM-Hospitalist-Compensation-Survey/. Accessed April 23, 2015

24. Johnson BA. A compensation system-self assessment tool: 12 questions for better results. Available at: http://www.mgma.com/Libraries/Assets/ Practice\%20Resources/Tools/Physician-Compensation-System-Self-Assessment-Tool.pdf. Accessed April 23, 2015.

25. de Winter JCF, Dodou D. Five-point Likert items: T-test versus MannWhitney Wilcoxon. Pract Assess Res Eval. 2010;15.

26. Altschuler J, Margolius D, Bodenheimer T, Grumbach K. Estimating a reasonable patient panel size for primary care physicians with team-based task delegation. Ann Fam Med. 2012;10:396-400.

27. Olson A. Primary-care physician compensation. Mt Sinai J Med. 2012;79:490-6

28. Kotter JP. Leading change: why transformation efforts fail. Harv Bus Rev. 1995;59-67. 